\title{
Acquired hepatocerebral degeneration: report of an atypical case
}

\author{
D. I. GRAHAM, J. HUME ADAMS, F. I. CAIRD, AND JOHAN W. LAWSON \\ From the University Department of Neuropathology, Institute of Neurological Sciences, \\ Glasgow, and the University Department of Geriatric Medicine and the Department \\ of Pathology, Stobhill Hospital, Glasgow
}

SUMMARY A case of acquired hepatocerebral degeneration secondary to biliary cirrhosis is described. It differs from the conventional type because of the clinical predominance of cerebellar ${ }^{\mathcal{N}}$ symptomatology and because the principal neuropathological abnormalities were restricted to the $\stackrel{\odot}{\vec{\circ}}$ pallidum and to the cerebellum.

Implication of the nervous system in the acquired (non-Wilsonian) type of chronic hepatocerebral degeneration may take the form of transient or permanent psychiatric or neurological disturbances. It is generally accepted that these sequelae are due to an extensive porto-systemic collateral circulation and not to the type of liver disease or to the portal hypertension per se.

The protean nature of the neuropsychiatric syndromes associated with chronic liver disease and an extensive porto-systemic collateral circulation has been reviewed by Summerskill, Davidson, Sherlock, and Steiner (1956) and by Read, Sherlock, Laidlaw, and Walker (1967). The commonest neurological disorder is a reversible encephalopathy-namely, hepatic precoma and coma. It is also recognized that there may be permanent damage to the brain (Baltzan, Olszewski, and Zervas, 1957; Gibson, 1963; Victor, Adams, and Cole, 1965; Read et al., 1967). The most comprehensive clinical, biochemical and pathological study has been carried out by Victor et al. (1965) who concluded from a series of 27 cases that there was a chronic and largely irreversible syndrome of remarkable neurological and neuropathological constancy associated with acquired liver disease and/or porto-systemic shunts. A permanent myelopathy has also been reported but is less widely recognized (Liversedge and Rawson, 1966; Pant, Rebeiz, and Richardson, 1968).

Reported here is a patient with an acquired form of chronic hepatocerebral degeneration who presented an unusual clinical picture and who at necropsy was found to have atypical neuropathological features.
CASE REPORT

CLINICAL HISTORY

J.H. (S.H.G. 32571), a retired coach builder, was 69 the time of his death in 1967. He developed dyspepsia䄱? 1940, a duodenal ulcer was demonstrated in 1952, and fre was first admitted to Stobhill General Hospital 4 n February 1960 with an exacerbation.

At laparotomy on 4 March 1960 (Mr. F. T. Crossling) a duodenal ulcer with pyloric stenosis and a small fibroptc gallbladder containing stones were found; posterwie gastroenterostomy and cholecystectomy were performed. After operation he developed obstructive jaundice, and on re-exploration 11 days later the biliary tree was foundo to be fibrotic but patent. A T-tube was inserted into thes common bile duct. Liver biopsy showed thickening of theo portal tracts, with lymphocytic infiltration, some pro-0 liferation of bile ducts, and bile thrombi, but normab hepatic parenchyma. He continued to have mild jaundice (see Fig. 1), and over the next few months had severa rigors. The T-tube was removed in September 1960 Thereafter he had further occasional rigors, and also melaena. In May 1961 the common bile duct was again. explored, and a stricture of the upper end divided and closed over a polyethylene tube. A stomal ulcer was found $\overline{0}$ and for this a vagotomy was performed. He was begun on: prednisone, which was given for six months, initially in a dose of $15 \mathrm{mg} /$ day. In July 1962 he was readmitted with melaena complicated by hepatic precoma.

Rigors and jaundice persisted, and in October 1962 he was admitted under the care of Professor S. Alstead. A음 barium swallow showed well-marked oesophageal varices, and a liver biopsy, fibrous widening of the portal tracts, proliferation of bile ducts, and lymphocytic infiltration but normal parenchymal architecture. His rigors were controlled by demethylchlortetracycline $150 \mathrm{mg}$ twicen daily, and he was also given vitamin $K$ and vitamin B 656 
complex. In January 1963 the chemotherapy was changed to ampicillin because of recurrence of rigors. In March 1965 vitamin D supplements were begun because of mild hypocalcaemia (serum calcium $8.6 \mathrm{mg} / 100 \mathrm{ml}$.), and in September, 1965 oesophageal varices were again demonstrated radiologically.

Figure 1 shows serial liver function tests from 1960 to 1967. It will be seen that the serum bilirubin was never entirely normal, the alkaline phosphatase almost always considerably elevated, the serum albumin low and the globulin usually raised to $4 \mathrm{~g} / 100 \mathrm{ml}$. Electrophoresis in October 1962 and again in July and September 1965 showed a considerable increase in $\gamma$-globulin.

In mid 1967 he developed progressive neurological symptoms for the first time. These consisted initially of tremor of the hands and slurring of speech, then unsteadiness in walking and difficulty in feeding due to ataxia. By early November he was unable to leave the house, and soon became virtually bedridden. He was occasionally confused and euphoric.

His last admission was on 15 December 1967. He was very wasted, with thin skin, senile purpura, and a red, raw tongue. There was moderate jaundice and generalized pigmentation, with a few spider naevi. The liver was palpable $3 \mathrm{~cm}$ below the right costal margin, and some could feel the spleen. His neurological state was remarkable. He was alert and cooperative and, though a little slow, was not substantially demented. His speech was barely intelligible because of an ataxic dysarthria. The fundi and pupils were normal, but there was poor ocular convergence. There was no nystagmus. There was bilateral facial weakness, but no definite weakness of the trunk or limbs. Tone was normal. There was very gross cerebellar ataxia of arms and legs, and in addition undoubted flapping tremor of hepatic type. The tendon reflexes were symmetrical and brisk, and the plantar responses flexor. There was no gross sensory loss.

The results of investigations were as follows: $\mathrm{Hb}$ $11.6 \mathrm{~g} / 100 \mathrm{ml}$.; WBC 4,400/c.mm, ESR $117 \mathrm{~mm} / \mathrm{hr}$. Prothrombin time was normal. Blood urea was $48 \mathrm{mg} / 100 \mathrm{ml}$.; electrolytes normal; serum calcium $9.0 \mathrm{mg} / 100 \mathrm{ml}$.; phosphate $2.3 \mathrm{mg} / 100 \mathrm{ml}$.; serum bilirubin $15.2 \mathrm{mg} / 100 \mathrm{ml}$.; alkaline phosphatase $50 \mathrm{u}$.; serum albumin $2.3 \mathrm{~g} / 100 \mathrm{ml}$., globulin $6.0 \mathrm{~g} / 100 \mathrm{ml}$.; thymol turbidity $8 \mathrm{u}$.; SGOT $80 \mathrm{u}$., SGPT $56 \mathrm{u}$. Serum iron was $42 \mu \mathrm{g} / 100 \mathrm{ml}$. Urine contained a trace of albumin. The CSF protein was $15 \mathrm{mg} / 100 \mathrm{ml}$., and it contained $1 \mathrm{WBC} / \mathrm{c} . \mathrm{mm}$. Chest radiograph was normal.

A diagnosis was made of biliary cirrhosis with chronic hepatocellular failure and hepatic precoma, and chronic cerebellar degeneration. He was treated with a no protein diet and oral neomycin. There was some improvement in his flapping tremor, but he developed profuse haematemesis and melaena, and died 14 days after admission.

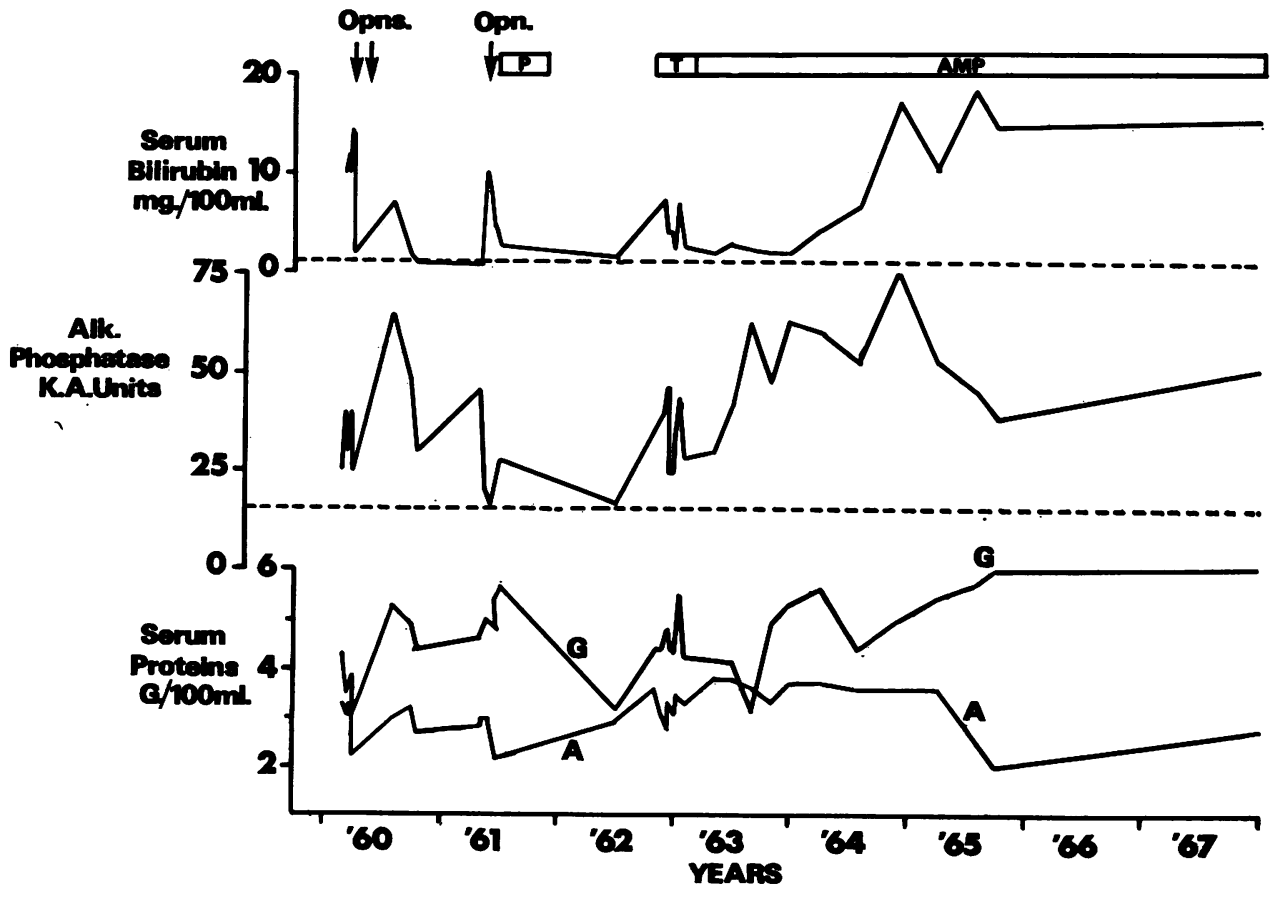

FIG. 1. Serial biochemical data from $1960-67 . \mathrm{P}=$ prednisone; $\mathrm{T}=$ demethylchlortetracycline; $\mathrm{AMP}=$ ampicillin; $\mathbf{G}=$ globulin; $\mathrm{A}=$ albumin . 
At no time was it thought that any of the drugs used in his management had contributed to the neurological illness.

\section{PATHOLOGICAL FINDINGS}

The stomach contained a cast of altered blood. The oesophageal varices were collapsed and, although the precise source of bleeding was not identified, there was no evidence of a recurrent peptic ulcer. Multiple adhesions were present in the right hypochondrium and a fistulous tract containing multiple mixed gallstones was identified between the first part of the duodenum and the left hepatic duct. A stone was present at the lower end of the dilated common bile duct. There was also a stricture between the common hepatic and right hepatic ducts. The liver weighed $1,200 \mathrm{~g}$ and was bile stained; on section there was a cirrhosis, the majority of the nodules measuring about $4 \mathrm{~mm}$ in diameter. Microscopy showed a coarse multilobular cirrhosis. The portal tracts were widened by fibrous tissue and infiltrated by lymphocytes and plasma cells. Many of the larger bile ducts were dilated and their lumina contained polymorphonuclear leucocytes. There was marked bile duct proliferation. The lobules were diffusely fatty and there was evidence of active necrosis of liver cells at the limiting plate. Foci of regeneration were seen too. Bile stasis within hepatic cords was evident but bile lakes were not a feature. The overall histological appearances were those of secondary biliary cirrhosis due to extrahepatic bile duct obstruction. Significant quantities of iron were not demonstrated by the Prussian blue reaction. The spleen weighed $370 \mathrm{~g}$ and a retroperitoneal porto-systemic anastomosis was demonstrated. An area of ischaemic fibrosis was identified in the wall of the left ventricle and there was bronchopneumonic consolidation of both lower lobes. The vertebral bone marrow appeared hyperplastic. No abnormalities were detected in the endocrine, urogenital, or osseous systems.

NEUROPATHOLOGY The brain (NP 68027) was suspended in $10 \%$ formol saline for three weeks before dissection. 으 The cerebral hemispheres were cut into coronal slices $Z$ $1.0 \mathrm{~cm}$ thick after transection of the mid-brain. The spinal cord was not available for examination.

Blocks from temporal (at anterior and posterior levelso including the basal ganglia), frontal, parietal, and 0 occipital lobes, cerebellum (both hemispheres), midbrain, pons, and medulla were embedded in celloidin and $\stackrel{\rho}{=}$ sections were stained by cresyl violet, luxol fast blue/cresyl $\stackrel{9}{2}^{\overline{2}}$ violet, Woelke's modification of Heidenhain's method for. myelin, and by the Holzer and Gros-Bielschowsky methods. Further blocks from the frontal lobe and basal ganglia were embedded in paraffin wax and stained byㄷ haemalum and eosin, haemalum-Van Gieson, PAS,ㅡㅡ methyl green pyronine, and the Feulgen technique. $\overline{\bar{D}}$ Frozen sections of the basal ganglia were stained by Sudan III and IV.

MACROSCOPIC APPEARANCES OF FIXED BRAIN $(1,160 \mathrm{~g})$ The only external abnormality was moderate cortical atrophyat the frontal and temporal poles. In coronal sections the only abnormalities were moderately well-defined pale grey areas affecting the greater part of the medial segment? of each globus pallidus (Fig. 2). The cerebellum and brain-stem appeared normal externally and on section

MICROSCOPIC APPEARANCES Basal ganglia There wẹं bilateral and essentially symmetrical sharply defined ares of rarefaction without fibrillary gliosis in the medial seggo ments of each globus pallidus, best seen in sections stained for myelin (Fig. 3). Within the affected areas there was considerable loss of neurones and axis cylinders $\square$ some of the residual axons were coarsely beaded amç numerous retraction balls were seen (Fig. 4). There was aD complete absence of sudanophilic or hypertroph microglial cells within the rarefied areas. Scanty petis vascular cuffing by lymphocytes was evident. Many large Alzheimer type II cells were seen in each globus pallidus in sections stained by cresyl violet they characteristically

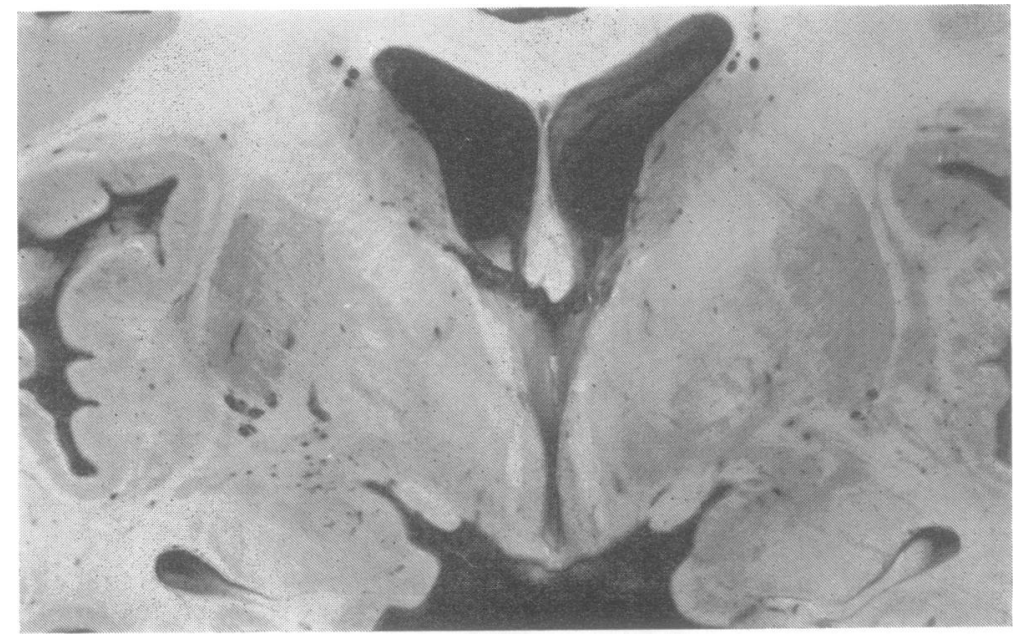

FIG. 2. Coronal section of brain showing pale grey areas in each globus pallidus, $\times 1 \cdot 3$. 


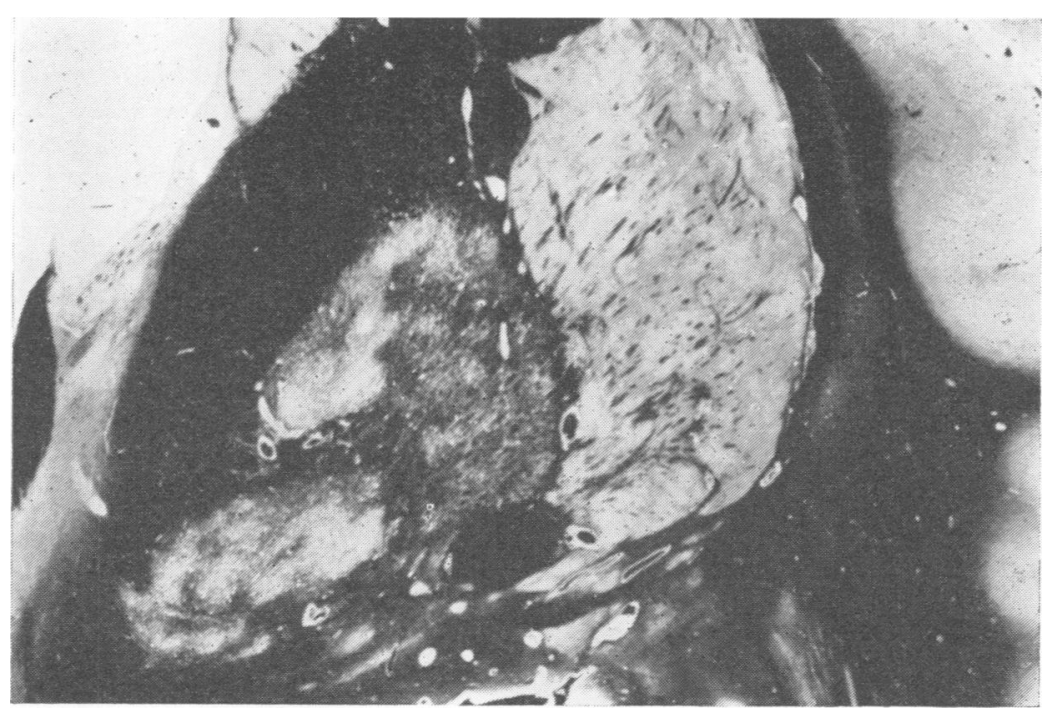

FIG. 3. Right basal ganglia. Rarefied areas in globus pallidus. Heidenhain's myelin, $\times 2$.

had scanty cytoplasm, perinuclear blue/green cytoplasmic granules, thin oval nuclear membranes, scanty or absent chromatin, and from one to three intranuclear inclusion bodies (Fig. 5). The nature of these inclusion bodies was not determined: an occasional one was PAS positive, but all were both methyl green pyronine and Feulgen negative. Opalski cells were not seen.

The internal architecture of the other basal ganglia was normal apart from the presence of many Alzheimer type II cells in the putamen, in the caudate, amygdaloid and subthalamic nuclei, and in the substantia nigra: they were not seen in the thalamus, in the geniculate and mammillary bodies, in the red nuclei, or in the hippocampi.

Cerebral cortex The cortical architecture was well pre- served and there was no apparent neuronal loss or gliosis. There were many Alzheimer type II cells, especially in layers 5 and 6 and at the cortico-medullary junction, but there was no polymicrocavitation. Hypertrophied microglial cells were seen in the deeper layers despite the absence of discernible nerve cell loss. All of these features were present in the frontal cortex, to a lesser extent in the parietal and temporal cortex, with the notable exception of the hippocampal gyrus, and minimally in the occipital cortex.

Central white matter Excessive numbers of astrocytes were seen at the cortico-medullary junction and in the digitate white matter of the frontal and parietal lobes and to a lesser extent in the temporal and occipital lobes.

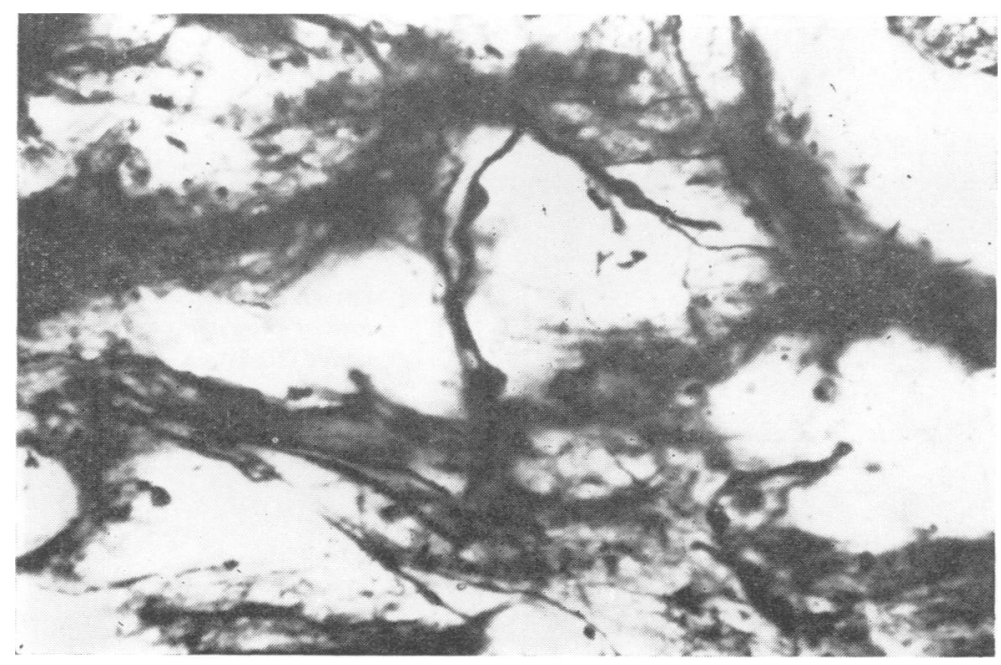

FIG. 4. Globus pallidus. Coarsely beaded axons and small cysts. GrosBielschowsky, $\times 525$. 


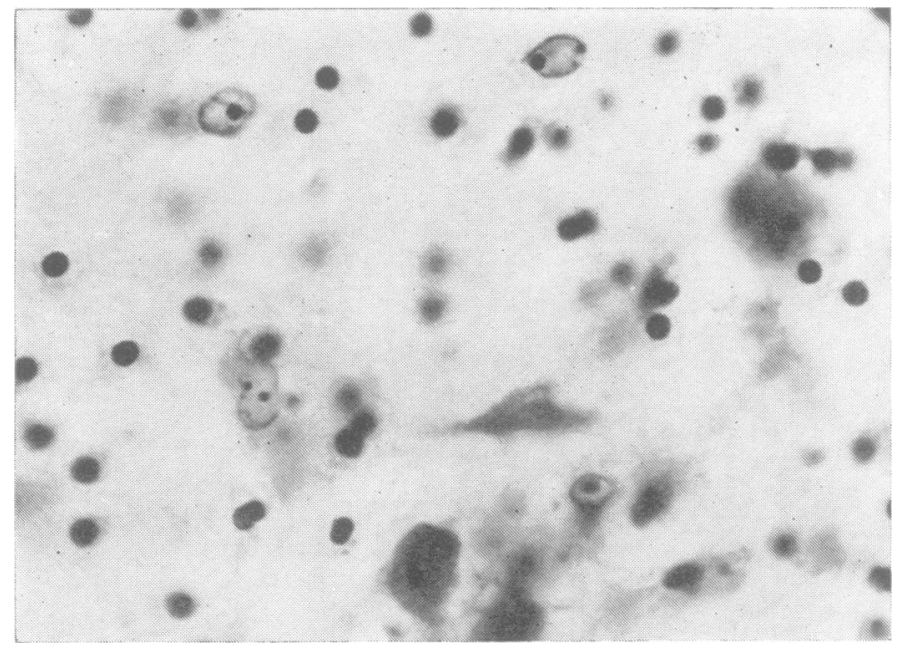

FIG. 5. Globus pallidus. Alzheimer type II astrocytes and degenerate nerve cells. Cresyl violet, $\times 525$.

Sections stained by the Holzer technique showed a diffuse fibrillary gliosis throughout the central white matter with periventricular accentuation. Gliosis, however, was not present in the internal capsule or in the white matter related to the basal ganglia but was seen in the optic tracts.

Brain-stem Alzheimer type II cells were limited to the inferior colliculi, the olives, and the cuneate and gracile nuclei. There was a diffuse fibrillary gliosis in the cerebellar peduncles, the substantia nigra, the tectal and tegmental parts of the mid-brain, and throughout the pons. No specific fibre tract degenerations were seen and in particular the pyramidal tracts appeared normal.

Cerebellum A moderate and diffuse loss of Purkinje cells was present throughout both hemispheres (Figs. 6 and 7). There was no accentuated loss in the vermis within the depths of sulci; some of the remaining Purkinjo cells were normal but others showed vacuolated and shrunken cytoplasm. There was obvious hypertrophy of Bergmann astrocytes and an increased number of glyab cells and a diffuse fibrillary gliosis in the molecular lagef The dentate nucleus was normal. Only occasionab Alzheimer type II cells were seen in the Bergmann lager and dentate nucleus.

\section{DISCUSSION}

The association between liver disease and struct changes within the central nervous system is $\overrightarrow{w e} \mathbb{b}$ known. This can take a number of forms. Foif instance in the precoma or coma of acute hepatie

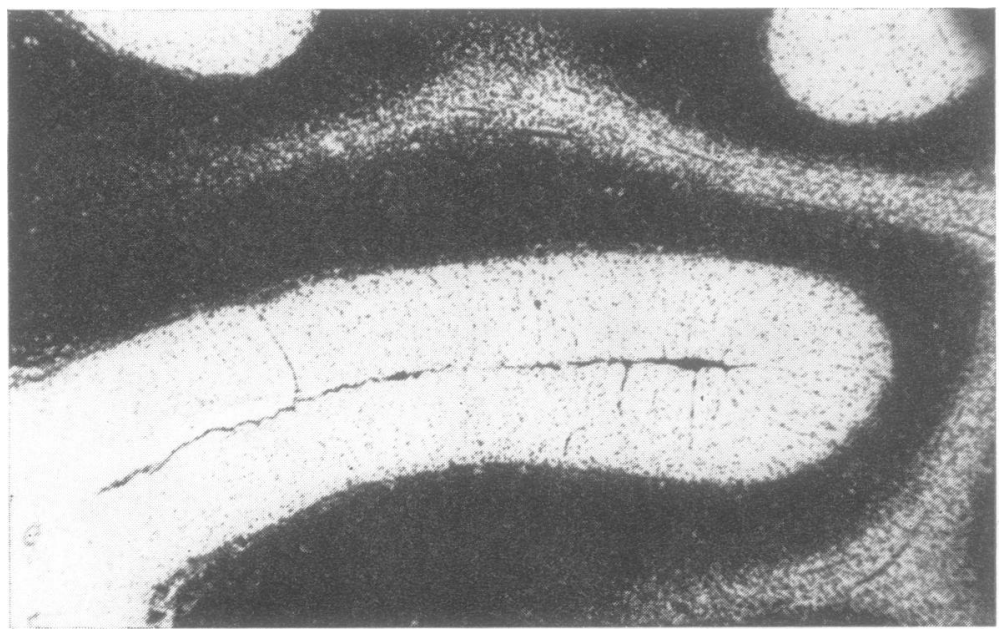

FIG. 6. Cerebellum. Subtota $\bar{P}$ loss of Purkinje cells. Cresyl violet $(30 \mu), \times 44$. 


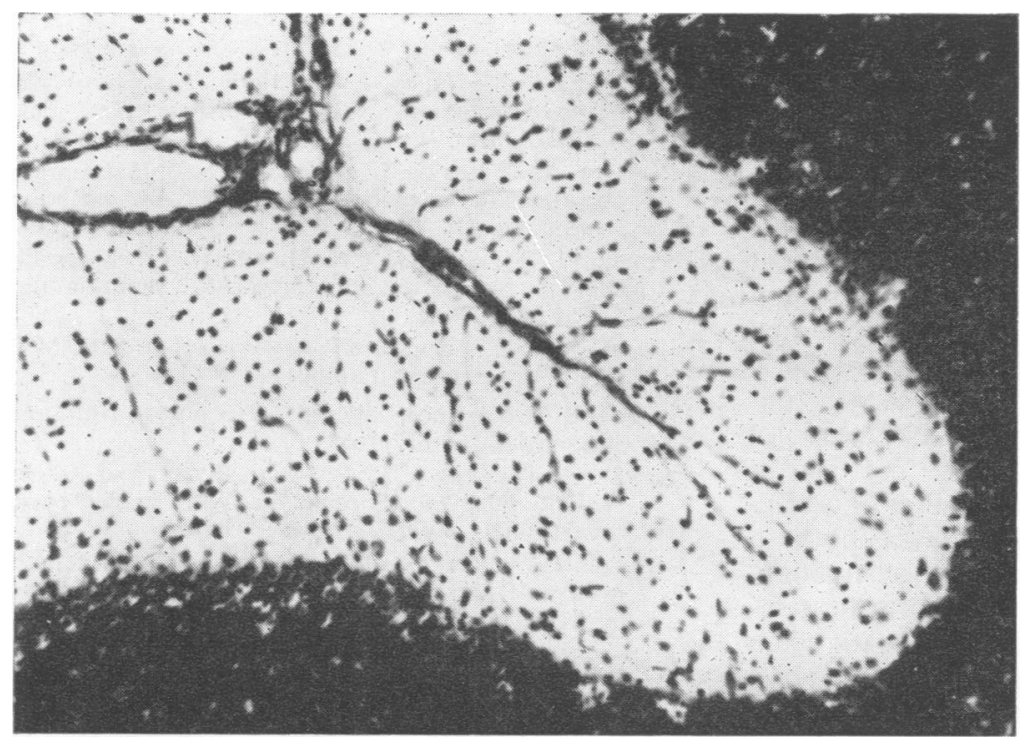

FIG. 7. Cerebellum. Loss of Purkinje cells and gliosis in molecular layer. Cresyl violet $(30 \mu), \times 125$.

failure there is diffuse hyperplasia of protoplasmic astrocytes in the grey matter of the cerebral cortex, cerebellum, and basal ganglia (Adams and Foley, 1953). In human cases these changes bear an approximate relationship to the duration and severity of the hepatic coma and precoma (Sherlock, 1968): in experimental animals the changes in astrocytes can be related to the level of the blood ammonia (Kline, Doberneck, Chun, and Rutherford, 1966; Doyle, 1967; Cavanagh and Kyu, 1969). The outcome of this potentially reversible state depends upon the functional integrity of the liver, the protein load presented to the gastrointestinal tract, and the extent of the porto-systemic collateral circulation.

Two types of chronic hepatocerebral disease are recognized. The familial or hereditary form of hepatolenticular degeneration-Wilson's diseasewith its attendant abnormalities of copper metabolism is the better documented. In recent years considerable attention has been paid to another entity, the so-called non-Wilsonian type of hepatocerebral degeneration. This takes the form of a slowly progressive neurological illness characterized by an encephalopathy and irreversible changes within the central nervous system. It is found in patients with chronic liver disease and an extensive portosystemic collateral circulation or with a portosystemic anastomosis (Baltzan et al., 1957; Gibson, 1963; Victor et al., 1965; Sherlock, 1968).

The syndrome has been fully documented in comprehensive articles by Victor et al. (1965) and Adams (1968). It consists of dementia, dysarthria, cerebellar ataxia, involuntary movements, and pyra- midal tract signs. The present case on his last admission to hospital was not obviously demented or confused; although cooperative and alert he was a little slow. He did, however, have gross ataxic dysarthria, cerebellar ataxia, and a flapping tremor. No pyramidal tract signs were elicited. The clinical features were therefore predominantly those of a cerebellar and basal ganglia disorder rather than a dementing one; these correlate well with the neuropathological observations. The absence of cortical lesions may account for the lack of dementia.

The major neuropathological changes found in the cases studied by Victor et al. (1965) consisted of a diffuse but patchy cortical degeneration with polymicrocavitation at the cortico-medullary junction and in the striatum, a diffuse increase in the size and number of protoplasmic astrocytes many of which contained intranuclear inclusions, and an uneven degeneration of nerve cells and fibres in the cerebral cortex (especially in the deeper layers), cerebellum, and lentiform nuclei. The parenchymal lesions in the basal ganglia were generally less severe than those in the cerebral cortex but were nevertheless present in all but three cases. The present case is of particular interest as nerve cell loss and polymicrocavitation were restricted to each globus pallidus and were not seen in either the striatum or cerebral cortex. Another feature of their cases was considerable loss of Purkinje cells that was always more severe in the vermis. Although there is subtotal Purkinje cell loss in each cerebellar hemisphere, the present case does not show accentuated involvement of the vermis. The present patient is also unusual in that his syn- 
drome followed an eight year history of extrahepatic biliary tree obstruction. Only two of the 27 cases described by Victor et al. (1965) were secondary to biliary cirrhosis (types unspecified), the great majority of them following upon post-necrotic cirrhosis.

The cerebral lesions in the two types of chronic hepatocerebral degeneration are very similar, so that an absolute distinction between them depends upon the presence or absence of a family history, abnormal copper studies, and Kayser-Fleischer corneal rings. Although a diagnosis of Wilson's disease was considered in the present case, copper studies were not undertaken and corneal rings were not sought because the clinical presentation was that of a cerebellar disorder and the patient's illness was known to be secondary to extrahepatic biliary tree obstruction.

The findings of Victor et al. (1965) further emphasized the close relationship between hepatic coma and the acquired permanent form of hepatocerebral degeneration though no constant relationship could be found, especially as the bouts of hepatic coma were extremely variable in frequency and severity; many of their cases, however, had experienced recurrent or prolonged episodes of hepatic coma. The present case experienced only two bouts of hepatic coma, one in June 1962 which lasted about 24 hours and another for some days before death. Both were precipitated by episodes of acute gastrointestinal bleeding.

\section{REFERENCES}

Adams, R. D. (1968). Acquired hepatocerebral degeneration. Handbook of Clinical Neurology. Vol. 6. Diseases of the Basal Ganglia. North Holland Pub. Co.: Amsterdam.

Adams, R. D., and Foley, J. M. (1953). The neurologicaf disorder associated with liver disease. Res. PubP Ass. nerv. ment. Dis., 32, 198-237.

Baltzan, M. A., Olszewski, J., and Zervas, N. (1957). Chronfie porto-hepatic encephalopathy. J. Neuropath. exp Neurol., 16, 410-421.

Cavanagh, J. B., and Kyu, M. H. (1969). Colchicine-like effect on astrocytes after portacaval shunt in rat Lancet, 2, 620-622.

Doyle, D. (1967). Porto-caval Anastomosis in Rats. M.D: thesis, University of Edinburgh.

Gibson, J. B. (1963). Encephalopathy after porto-caval shunt Brit. med.J., 1, 1652-1655.

Kline, D. G., Doberneck, R. C., Chun, B. K., and Ruther(̄) ford, R. B. (1966). Encephalopathy in graded porta caval shunts. Ann. Surg., 164, 1003-1012.

Liversedge, L. A., and Rawson, M. D. (1966). Myelopath in hepatic disease and portosystemic venous anastomosis. Lancet, 1, 277-279.

Pant, S. S., Rebeiz, J. J., and Richardson, E. P. (1968) Spastic paraparesis following portacaval shuntsw Neurology (Minneap.), 18, 134-141.

Read, A. E., Sherlock, S., Laidlaw, J., and Walker, J. G. (1967). The neuro-psychiatric syndromes associate with chronic liver disease and an extensive portal systemic collateral circulation. Quart. J. Med., 36 135-150.

Sherlock, S. (1968). Chapter 5. Diseases of the Liver \&ng Biliary System. Blackwell Sci. Publ.: Oxford Edinburgh.

Summerskill, W. H. J., Davidson, E. A., Sherlock, S., 음영 Steiner, R. E. (1956). The neuro-psychiatric syndromg associated with hepatic cirrhosis and an extenspve portal collateral circulation. Quart. J. Med., esp 245-266.

Victor, M., Adams, R. D., and Cole, M. (1965). The acquiped (non-Wilsonian) type of chronic hepatocerelat degeneration. Medicine (Baltimore), 44, 345-396. 